\title{
Managing innovation through customer coproduced knowledge in electronic services: An exploratory study
}

\author{
Vera Blazevic • Annouk Lievens
}

Received: 2 July 2007 / Accepted: 4 July 2007 / Published online: 24 July 2007

(C) Academy of Marketing Science 2007

\begin{abstract}
Marketing theory and practice both recognize the increasing importance of customer collaboration for service provision and innovation. As part of such customer collaboration, customers of electronic services coproduce knowledge in varying degrees. An evolving phenomenon, knowledge coproduction has yet to receive much research attention; we therefore conduct a qualitative study of the roles customers play in knowledge coproduction and their resultant influence on different innovation tasks from a service provider view. Data from three electronic service interaction channels, involving managers, engineers, and customers; case study findings; and an extensive literature review indicate the importance of knowledge coproduction by customers and its ability to improve different tasks substantially during innovation activities. The results show three different roles of customers in knowledge coproduction and explain comprehensively how each role impacts various innovation tasks.
\end{abstract}

Keywords Customer collaboration · Knowledge creation . Innovation

V. Blazevic $(\bowtie)$

Faculty of Economics and Business Administration, Department of Marketing, Maastricht University, P.O. Box 616, 6200 MD Maastricht, The Netherlands e-mail: v.blazevic@mw.unimaas.nl

A. Lievens

Faculty of Applied Economic Sciences,

Department of Marketing, University of Antwerp,

Prinsstraat 13,

2000 Antwerp, Belgium

e-mail: annouk.lievens@ua.ac.be

\section{Introduction}

Marketing theory recognizes the increasing importance of customer collaboration in service provision (Vargo and Lusch 2004). Through customer collaboration organizations learn, meet customer requirements better, and improve performance (Prahalad and Ramaswamy 2004). Customers offer a wide base of skills, sophistication, and interests and represent an often untapped source of knowledge. Companies that draw on the knowledge of their customer base can capitalize on customer competencies for use during the course of their innovation activities.

Research on customer collaboration has investigated customer coproduction (Bendapudi and Leone 2003), the use of self-service technologies (Dabholkar and Bagozzi 2002; Meuter et al. 2005), and customer voluntary behavior (Bettencourt 1997) to demonstrate how customer and company roles converge. Furthermore, research in innovation suggests involving customers by providing them with toolkits to create their own innovations (e.g., von Hippel and Katz 2002) or talking to lead users during the innovation process to better understand early adopters (Lilien et al. 2002; Nambisan 2002). Similarly, Urban and Hauser (2004) discuss the advantages of "listening in" to examine new combinations of customer needs and identify opportunities for innovation. The majority of innovation research considers information acquisition of customer needs through regular face-to-face meetings, personal interviews, focus groups, and surveys. Although these techniques clearly are useful, the increased connectivity and possibilities of information technology (IT) open new opportunities for coproducing knowledge. Electronic interaction channels can help companies engage in ongoing dialogues, through which they may 
achieve mutual understanding and interpretations with customers. Although online communication lacks nonverbal cues, and therefore could never substitute for all face-to-face interaction, it represents an additional means for interactions. Existing research has not considered how knowledge coproduced by customers in electronic service provision might be used for innovations.

Knowledge coproduction by customers pertains to more than simply providing customers access to an organization's knowledge base or seeking their involvement in innovation (Sawhney and Prandelli 2000). Consistent with Lusch and Vargo's (2006) conceptualization, we define knowledge coproduction as the degree to which customers and companies create new knowledge through mutual interactions. Knowledge represents the only true basis for sustainable competitive advantage because it is the operant resource that potentiates service (Lusch et al. 2007). The purpose of this research is to identify how companies may use electronic services, such as self-service technologies and virtual communities, systematically to coproduce knowledge with customers for different innovation tasks. Our research addresses several Marketing Science Institute top-tier research priorities; it explores processes for the proactive understanding of customer needs and considers how customer knowledge is communicated within the firm to achieve innovation purposes.

Considering the exploratory nature of our research question, we conduct a case study pertaining to a leading global computer service company. We also investigate different electronic interaction channels with varying degrees of knowledge coproduction. ${ }^{1}$ Both desk research and in-depth interviews with managers, engineers, and customers, along with a literature review, serve as the basis for our theory development.

The remainder of our article is structured as follows: We start by detailing relevant previous research before describing our research method. Thereafter, we present our findings with respect to the roles of customers in knowledge coproduction and their impact on different innovation tasks. Finally, we conclude by delineating various implications and further research suggestions.

\section{Previous research}

Research that has addressed company-customer collaboration issues mainly originates in two literature streams: services marketing and innovation.

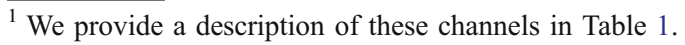

Company-customer collaboration in services marketing

Within the services marketing domain, a plethora of studies have addressed various degrees of customer participation during the service encounter (e.g., Bendapudi and Leone 2003; Bettencourt 1997; Lovelock and Young 1979; Meuter et al. 2000). Some literature on customer participation centers on its positive outcomes for companies, such as cost reductions (Bowers et al. 1990), increased economic efficiency (Lovelock and Young 1979), and customer satisfaction (Bendapudi and Leone 2003; Meuter et al. 2000). Whereas the first two outcomes focus on monetary gains, the latter examines the psychological effects of customer coproduction. Other research within this stream concentrates on strategies to manage customer participation and argues that customers should be treated as partial employees (e.g., Kelley et al. 1990). Another subset of literature focuses on the roles customers perform (Bitner et al. 1997), including customers as productive resources, value contributors, and competitors to the service organization. In addition to these roles, Bettencourt (1997) examines customer voluntary behavior, such as cooperation, in which the customer is a human resource, and participation, in which the customer acts as an organizational consultant. Taking a constructivist perspective, Aubert-Gamet (1997) discusses when and how customers become cobuilders of the service space. However, these research studies focus on customer roles in face-to-face encounters. Research that moves beyond those face-to-face joint production situations studies the trial and adoption of self-service technologies (e.g., Dabholkar and Bagozzi 2002; Meuter et al. 2000, 2005) by investigating situations in which customers produce services for themselves without interacting with firm employees.

None of this research considers the roles of customers in electronic service delivery. Furthermore, the role of the customer is changing "from isolated to connected, from unaware to informed, from passive to active" (Prahalad and Ramaswamy 2004, p.2). Therefore, companies might move beyond exploiting customer knowledge by shifting toward knowledge coproduction (Sawhney and Prandelli 2000). The pervasiveness of the Internet has facilitated a cost-effective mechanism to enable interactions between customers and organizations and among customers. This communication process increasingly entails a continuous dialogue (Vargo and Lusch 2004), such that knowledge is created not by an individual mind but rather through activities and interactions. That is, when they interact, companies and customers coproduce knowledge. As coproducers, customers embody highly relevant skills and knowledge and, consistent with the service-dominant (S-D) logic, serve as exchange partners of a company who engage in joint processes for mutual service provision (Lusch et al. 2007). No research has investigated the roles customers take during knowledge 
coproduction in electronic services, so to address this gap, we investigate the following research question:

Can we identify specific customer roles for knowledge coproduction in electronic services?

\section{Company-customer collaboration in innovation}

Research into innovation addresses customer collaboration issues as well. The evolution and transformation of customers from passive buyers to active value cocreators (Prahalad and Ramaswamy 2003) appears, for example, in Procter \& Gamble's (P\&G) "P\&G Advisors" program, through which customers help P\&G develop new products by testing new items and providing feedback. The advances in IT enable companies and their network partners to experience increased connectivity and network ubiquity (Lusch et al. 2007). This is reflected in electronic service delivery, which facilitates network collaborations and causes companies to turn increasingly to customers for innovative ideas. Such collaborative competence also facilitates the company's absorptive and innovative capacity to compete in dynamic, complex environments (Lusch et al. 2007).

Most research within this area employs the lead user approach, based on studies by von Hippel (e.g., Alam 2002; von Hippel 1986). In this context, users become manufacturers rather than initiators of innovation (Lilien et al. 2002), and lead users expect an attractive return for their innovation efforts.

However, lead users are scarce and only relatively few lead users can be involved in innovation because of coordination constraints. Therefore, Urban and Hauser (2004) propose "listening in" on customer dialogues during Internet searches. Such monitoring enables companies to identify desired but currently unfulfilled needs of customers, reveals opportunities for innovation, involves a larger group of customers, and provides the company with continuous, upto-date information. Just as the S-D logic requires companies to focus on marketing with customers rather than to customers (Vargo and Lusch 2004), companies could innovate with customers rather than to customers and thereby actively involve customers in the innovation process. Von Hippel and Katz (2002) also propose that companies could reduce the costs of identifying need-related information by providing customers with user toolkits for innovation. With these toolkits, customers receive a set of design tools to develop innovations with their own desired features. Thus, the increased connectivity between companies and customers enables firms to innovate with a relatively larger group of customers in a cost-effective, continuous manner. However, despite this ongoing research into customer collaboration for innovation, no research addresses how customer coproduced knowledge contributes to various innovation tasks. Because innovation is not a discrete event, but rather involves a series of tasks (Yadav et al. 2007), we explore the increased innovation opportunities offered by electronic means and investigate the following research question:

How can customer knowledge coproduced in electronic services be of benefit to various innovation tasks?

\section{Materials and methods}

This study is of an exploratory nature, aiming to acquire a more fundamental understanding of the role customers play in knowledge coproduction and their respective influence on different innovation tasks. Moreover, this research area is relatively new and represents an underresearched phenomenon. We actually know very little on what determines customer collaboration, how this phenomenon contributes to foster valuable knowledge creation and hence the customer's role and input during the innovation process. The latter constitutes a complex process in which innovation uncertainty and customer behavior has to be linked in a service provision context. Few hands-on constructs or theories can help us to clarify and develop a profound conceptual framework in this area. As a result, qualitative research is best suited to tackle this research problem and provide an in-depth insight into the roles of customers in knowledge coproduction and their resultant impact on different innovation tasks.

Specifically, we employ a case study approach, defined as "an empirical inquiry that investigates a contemporary phenomenon within its real-life context; when the boundaries between phenomenon and context are not clearly evident; and in which multiple sources of evidence are used" (Yin 1994, p. 13).

We use a multiple case design to trace the knowledge coproduction process in different electronic services by participating in different teams responsible for managing knowledge gathered from different electronic services. This design offers a strong foundation on which to build our theory; the similarity of the organizational context suggests meaningful comparisons across the different electronic services, and the differences in the customer service approaches of each channel provide a reasonable basis for generalizability.

In line with grounded theory, a case study research and a literature review were used as a platform for theory development. Reflective reasoning (Miles and Huberman 1994) entered the research process and has led to theory building. As in grounded theory, our data analyses has followed a well-defined process starting with basic descriptions and has finally moved into conceptual ordering and then to theory development. In fact, consistent with grounded theory we combined two data analysis processes 
(Glaser and Strauss 1967). In a first process we coded all data, breaking them down and comparing them, while in a second process we placed data in a category, thereby contributing to theory development. Coding was considered as an iterative, inductive process from which we constructed descriptions and hence derived theory.

\section{Research context}

Our case study research design, involving a leading global computer services company, is well suited to our research, because this industry is well known for mutual interactions with customers, and companies compete on the basis of service innovation. To address our first research question, we must study an industry that uses a wide variety of electronic services. The focal company in this study has several electronic service channels with different customer collaboration levels. Furthermore, the industry we study has a long history of developing innovations (Jeppesen and Frederiksen 2006). For example, IBM and a handful of its business partners will spend $\$ 250$ million this year to develop worldwide partner innovation centers and facilitate joint innovation development. Many customers have been exposed to open source movements and are relatively accustomed to collaborations in knowledge creation and innovation. Therefore, this research context is an appropriate setting for studying how customers can contribute to innovation activities.

\section{Data collection}

The intensive data collection lasted more than a year and included interviews, observations of online meetings, company documentation, and customer documentation. The lead author spent 1 day per week over a period of 6 months within the company to achieve a better insight into how the company operates, the organizational culture, and so forth. The second author remained distant from the company.

Extant theory provides the selection criteria of the chosen cases. A manager from the electronic service delivery team served as the focal contact and knew of the case selection criteria. To maximize our research validity, we asked the contact manager to select electronic interactions that fulfilled the following criteria: (1) The company currently uses that electronic interaction channel and (2) customers are involved in varying degrees of knowledge coproduction. In response, we selected three electronic interaction channels, in which customers coproduce knowledge in varying degrees through the company's systems, provide feedback to the company, or produce information in the customer community. We provide an extensive description of the three different electronic interaction channels in Table 1.
The data collection methods of our case study research include both desk and field research. First, we conducted desk research to identify data that already existed in internal company documents and obtain a good understanding of the company's marketing and technology strategies. In total, we received 205 pages of internal documentation. In addition, we monitored the online technical support community discussions and gathered 189 pages of different community discussions from both very active and less active content subcategories, using the copy-and-paste function. The lead author also maintained a diary of observations and impressions, which amounted to 78 pages. Second, we perform field research through in-depth interviews with key informants for each channel (e.g., electronic service program leaders, general e-service business managers, marketing managers, program team members, engineers, customers of the community). Qualitative research generally uses purposeful, conceptual sampling instead of random sampling, so our sampling strategy is driven by theory rather than representativeness (Miles and Huberman 1994). To avoid bias, we did not communicate the selection dimension to the interviewed employees.

For the first electronic interaction channel (system usage), we interviewed the entire worldwide team (9 managers) responsible for this particular service. Similarly, in the second channel (feedback provision), we interviewed 11 managers from the team in charge. In the third channel (online technical support community), we used not only the 7 responsible managers but also 8 engineers and 7 active customer participants in the community. The interviews lasted 1 to $2 \mathrm{~h}$ and involved a questionnaire with open-ended, exploratory questions. The questionnaire checklist ensured we address (1) the strategy for the service channel, (2) the role customers play in knowledge coproduction, (3) the manner in which the company handles customer knowledge, (4) how customer knowledge contributes to innovation, and (5) how customers evaluate the service channel. We recorded all interviews and transcribed them immediately afterward. In Table 2, we describe each informant, his or her job roles, the length of the interview, the number of transcript pages, and his or her duration as a member of the online community.

\section{Data analysis}

We use the collected data to perform a thematic content analysis through an inductive process (Holsti 1969) in which we move from observation to hypotheses development. We progress from categorization to abstraction, comparison, dimensionalization, integration, iteration, and refutation, as suggested by Spiggle (1994). Specifically, we categorize all case study data (e.g., interview transcripts, observation notes, internal documentation, community discussions) into content 
Table 1 Different electronic interaction channels

Short description
Self-service technology
Customers search the knowledge content
Web sites of the organization to find
solutions to their problems. Online search
behavior is tracked and used to identify the
most requested documents. These
documents are then presented as frequently
asked questions (FAQs). Customers are not
aware that their online behavior is used
Proactive feedback provision
Customers proactively provide feedback
about the company's products and services.
On each Web page, customers can click on
an online form to provide opinions about
the product or service. Customers receive
reactions from the company

Customer virtual community

An online technical support forum on which customers provide technical advice and interact socially with others. The company provides the technical platform and moderates the discussion boards to avoid swearing and inappropriate language (e.g., user names like "Osama bin Laden" get removed)

Strategic objective

Service delivery

Locate and present the documents that customers use most often to solve their problems. The company wants to show customers how they can help themselves by providing technical documents in a simple, fast, convenient way

Customers express their concerns and problems with products and services. Customer feedback indicates whether the company is on track in its services, products, and strategies. The company gains low-cost information about customer perceptions. Feedback provides the company with ideas, and impulses for changing existing and developing new products and services

To be the meeting place for IT professionals to collaborate peer-to-peer and enable the exchange of best practices and ideas. Information exchanges result in an IT community that has a community-wide understanding of common IT problems and solutions
Customer usage behavior, according to which documents are frequently opened and read, receive positive feedback, and resolve special requests/situation. Customers with a support contract can access this service and search for solutions to their problems

Service delivery is through e-mail when customers receive a reaction by the company that includes a statement about how their feedback has helped the company improve the products and services and especially the knowledge content of the Web sites

Freely accessible, because customers mainly interact with other customers. The service is delivered through online discussion boards on which users can ask and answer questions after registering themes related to knowledge coproduction before abstracting the resultant categories into higher-order conceptual constructs. We then compare the differences and similarities across incidents, as well as with relevant literature, which we gathered from various research areas, including services marketing, information systems, virtual communities, and innovation management. After we dimensionalized the data by identifying the attributes and characteristics of the different constructs, we moved to integration, which required lengthy discussions about the different emerging themes. Because the lead author had developed a close relationship with the company whereas the second author remained distant, interpretive tension existed and improved the integration process. We also downloaded additional threads from the online community to look for counterexamples and challenge our interpretations. Furthermore, during the course of our case study research, we organized several feedback sessions with the contact manager from the electronic service delivery team, who provided the necessary context variables we needed to obtain more finegrained insights into the processes and some findings. Moreover, the feedback enabled us to steer and change our data collection procedures if necessary to assess the plausibility of our interpretations and search for new cues. For each electronic interaction channel, we prepared a detailed report of our findings, which we sent to all participants; similarly, we provided the results for each case to the interview partners during feedback sessions, which entails our iteration and refutation steps. In summary, we validate our insights through prolonged engagement at the company's site; comprehensive, descriptively rich data from various sources; and verification of our results with respondents.

\section{Results}

Customer knowledge coproduction roles in electronic services

We identify three roles customers play during knowledge coproduction: passive user, active informer, and bidirectional creator. These roles differ in the degree of active knowledge coproduction. 
Table 2 Informant information

\begin{tabular}{llll}
\hline $\begin{array}{l}\text { Name } \\
\text { (disguised) }\end{array}$ & Job role & $\begin{array}{l}\text { Length of } \\
\text { interview } \\
\text { (minutes) }\end{array}$ & $\begin{array}{l}\text { No. of transcript pages } \\
\text { (times 12, double) }\end{array}$ \\
\hline
\end{tabular}

\begin{tabular}{|c|c|c|c|c|}
\hline \multicolumn{5}{|c|}{ Self-service technology } \\
\hline Evan & Manager for service delivery productivity tools & 40 & 4 & \\
\hline Paul & Manager for service delivery productivity tools & 60 & 8 & \\
\hline Tony & Worldwide knowledge team, Integration manager & 40 & 5 & \\
\hline Charles & Program manager of system usage team & 60 & 8 & \\
\hline Jack & Member of worldwide hardware knowledge team & 45 & 6 & \\
\hline James & Knowledge strategist & 45 & 6 & \\
\hline Jeremy & Manager of knowledge integration & 65 & 10 & \\
\hline Kirsten & Knowledge strategist & 35 & 4 & \\
\hline Michael & Knowledge engineer & 40 & 4 & \\
\hline \multicolumn{5}{|c|}{ Proactive feedback provision } \\
\hline Beverly & Complaint management for large clients & 50 & 7 & \\
\hline Ulrich & Manager for service delivery productivity tools & 40 & 3 & \\
\hline Arthur & Worldwide knowledge team, R\&D manager & 45 & 5 & \\
\hline George & Manager for service delivery productivity tools & 50 & 6 & \\
\hline Luke & Electronic operations team member & 40 & 5 & \\
\hline Matthew & $\begin{array}{l}\text { Program manager for specific electronic services } \\
\text { (business development) }\end{array}$ & 50 & 6 & \\
\hline Penelope & Manager in customer loyalty team & 45 & 6 & \\
\hline Pamela & Program manager for specific electronic services & 45 & 6 & \\
\hline Peggy & Electronic operations team member & 45 & 6 & \\
\hline Teresa & Team member of Web service management & 70 & 9 & \\
\hline Timothy & Program manager for electronic service delivery & 50 & 6 & \\
\hline \multicolumn{5}{|c|}{ Customer virtual community } \\
\hline David & Operations manager & 65 & 10 & Since 2001 \\
\hline Jason & Regional e-service manager & 55 & 7 & Since 2000 \\
\hline Joe & Inbound marketing manager & 70 & 10 & \\
\hline Matthew & Program manager for specific electronic services & 65 & 9 & \\
\hline Patrick & Country e-service manager & 60 & 9 & \\
\hline Robert & Development manager & 90 & 15 & \\
\hline Jim \& Edgar & Team members of country e-service & 50 & 8 & \\
\hline Adam & Response center engineer & 45 & 7 & Since 2000 \\
\hline Fred & Response center engineer & 45 & 6 & Since 2001 \\
\hline Morten & Response center engineer & 40 & 6 & Since 2002 \\
\hline Marcus & Response center engineer & 35 & 5 & Since 1997 \\
\hline Peter & Response center engineer & 40 & 5 & Since 1998 \\
\hline Sarah & Response center engineer & 45 & 6 & Since 2000 \\
\hline Tom & Response center engineer & 40 & 5 & Since 1999 \\
\hline Tess & Response center engineer & 40 & 5 & Since 2000 \\
\hline Aaron & Customer - mainly system administrators in various industries & 45 & 7 & Since 1997 \\
\hline Martin & Customer - mainly system administrators in various industries & 65 & 10 & Since 1997 \\
\hline Philip & Customer - mainly system administrators in various industries & 55 & 8 & Since 1996 \\
\hline Ruth & Customer - mainly system administrators in various industries & 50 & 8 & Since 1998 \\
\hline Sammy & Customer - mainly system administrators in various industries & 55 & 8 & Since 2001 \\
\hline Sean & Customer - mainly system administrators in various industries & 45 & 6 & Since 2000 \\
\hline Wayne & Customer - mainly system administrators in various industries & 70 & 8 & Since 1997 \\
\hline
\end{tabular}

\section{Customers as passive users}

The passive user role entails a very low level of knowledge coproduction and mainly occurs in electronic self-service channels. Customers search for solutions to their problems, and companies track this behavior to identify the most common problems and deliver appropriate solutions. The company uses a mathematical algorithm that is designed specifically to select the most requested documents according to how many times a document is opened, how long the documents remain opened, and how many unique users open the document. 
When customers are passive users, they are unaware that their behavior is tracked and the information used to create a described service. Their knowledge coproduction activity is quite low and unconscious, and employees therefore make conclusions solely on the basis of their behavior, as a member of the electronic operations team [Peggy] notes:

You can learn a lot of things from that, although there is not a direct interaction between our company and the customer. They [the customers] give indirect feedback through their action with the document, and this action is tracked. We know exactly the sequence of action. I take the input and I look at their behavior and then try to understand the perception of customers.

Although these customers are not aware of their knowledge coproduction, companies with electronic service channels can still exploit their usage behavior as an important information source. The acquired information is helpful and representative of many customers, as the program manager for a specific part of electronic services [Pamela] describes:

We have a data warehouse where all customer clicks are stored. There, I can access the customer behavior history for all customers. Then, I can consolidate all the information for each service. The customer behavior gives us a representative picture of what customers are experiencing.

Thus, the major advantage of knowledge coproduced by passive users is its representativeness, because customer online behavior information is aggregated over all customers participating in the online self-service technology. Some research already proposes that customers are resources that can help companies provide an effective service delivery system (e.g., Lengnick-Hall 1996) but mainly considers customers as product users during testing (Dolan and Matthews 1993; Nambisan 2002). The passive user role is different, in that the company observes all users who visit the knowledge database and search for solutions to their problems with existing products. In a sense, this approach is similar to clickstream techniques often employed to analyze purchase or browsing behavior to improve Web stickiness (Sismeiro and Bucklin 2004). Such real-life customer behavior provides a rich source of observed inmarket behavior (Urban and Hauser 2004). In summary, in their role of passive users, with their relatively low level of knowledge coproduction, customers are not aware that their behavior creates knowledge for the company, but that knowledge is representative and continuous.

\section{Customers as active informers}

Tracking customer behavior is useful but does not provide the company with information about the perceptions customers have of their service. Therefore, customers may also play roles as active informers, according to a manager for service delivery engineering productivity tools [Paul]:

It would be good, if we could find out what the customers really need to know. We could use it for our whole knowledge management program. We often use our gut feeling and try to put ourselves in the customers' shoes. Our algorithm tells us which documents are accessed, but not whether the document was helpful. Documents that are large often get a lot of hits because many keywords are found within the document.

That is, the company needs customers to perform more active roles; when customers are active informers, they point to problem areas in online documentation, service delivery, or products and services. Thus, they provide information about problem areas but do not deliver solutions. With self-service technology, customers can always click on a feedback form to express their concerns, critiques, and positive experiences. Similarly, customers inform the company and other customers about their problems with products, services, and service delivery in the customer community forum, which companies can use to look specifically for problems to which customers cannot find a solution, as a program manager for a specific part of electronic services [Matthew] states:

From the feedback, we learn what customers like to see in the future; we also learn what documentation is not clear to them. So there, we need to improve our documentation. We can also detect certain trends when many customers ask for similar things.

Furthermore, customers inform the company about many different aspects. The program manager for electronic service delivery [Timothy] explains:

It starts with the basic things, like it is difficult to navigate on your page. Customers also realize our actions. For example, our availability of services was very low last year. Customers came back to us and said that they saw our efforts. We were sure that we did not waste money and time. We also receive information on services that we do not provide directly, e.g., the telephone support has long waiting times. We take this information and transfer it to the correct person to action it. There is a wide range of different information categories.

Customers become active informers because they hope their information will help the company serve them better. Previous research partially recognizes this role in its discussion of customers as resources (Lengnick-Hall 1996; Nambisan 2002) but only addresses the input customers provide during the service process itself. We regard customers 
as active informers when they provide feedback even if they currently are not engaged in a service interaction, such as when they complain. That is, as a result of being active informers, customers benefit from improved products and services but also can express their frustrations, as a customer complaint manager [Beverly] realizes:

The customers benefit from raising their voice. It is good for them because they know they have a channel where they can express their frustration as well as their happiness with the system. They also hope that the problems they had in the past will diminish, as the content and the access is improved.

When customers are active informers, they also expect the company to be more receptive to their information, as greater sophistication prompts them to be more sensitive to the company's activities. Furthermore, whereas information from a passive user is not visible to other customers, that from an active informer can be both invisible and visible, depending on the interaction channel. When the customer decides to act as an active informer through the Web site feedback form or e-mail, his or her information remains invisible to other customers, but in the community forum, customers provide visible information, as the community operations manager [David] points out:

In the past, we have used the community to test new product areas. It is a very easy way to sense customers and receive information from them. The spectrum of possibilities to receive feedback has increased. Additionally, we get feedback on how well our community and our services are performing.

If companies actively encourage customers to act as active informers, they may receive information about perceptions of their current services and whether they need to improve existing or develop new services. Although customers as active informers represent a very useful source of information, they must engage themselves, and not all customers are willing to do so. Because only a limited number of customers provide feedback, companies should recognize the information gathered from active informers might not be representative. The program manager for electronic service delivery [Timothy] explains:

We are used to gathering information from some customers, but today this information is not always representative. That is a problem. We need a larger set of customers that confirm the information we have collected. This information would confirm that our [new product development] teams are developing products and services many customers want.

Finally, active informers engage themselves in coproduction activities by proactively communicating anticipated problems and being flexible toward the company, in line with Gruen et al. (2000) proposal that increased knowledge of the customer, obtained through coproduction activities, is a key requirement of providing increased value. Companies can develop a richer feel for problem areas through the interactional context of customers. In summary, in the role of active informers, a medium level of knowledge coproduction, the customer reports problem areas but does not offer any solutions. However, companies must determine whether the information that active informers provide is applicable to a wide range of customers.

\section{Customers as bidirectional creators}

When customers are passive users or active informers, the company-customer interaction is unidirectional; either the behavior of the customer triggers knowledge or the customer-provided information leads to new insights. However, when customers become bidirectional creators, these interactions also are bidirectional. For example, virtual customer communities, or online groups of customers who collectively coproduce and consume information about a shared item of interest, provide useful platforms for these interactions because customers participate in rich exchanges with the company and/or among themselves, and help companies identify problem areas. However, a bidirectional creator (i.e., a content-contributing customer in an online community) not only informs companies about problem areas but also makes suggestions and provides solutions and thereby coproduces new knowledge. In the customer community, customers also provide solutions to one another that may go beyond the knowledge provided by the company, as a customer [Aaron] points out:

I sometimes had questions that the company support never answered satisfyingly. In contrast, in the community you get a lot of hints and stimulation and often even answers from other customers. Moreover, the company employees also learn in the community, especially the technical engineers.

This knowledge is not focused on a specific aspect. Instead, the communities cover a wide range of topics, as another customer [Ruth] notes:

There are all kinds of different topic categories where you can access a lot of different knowledge. Furthermore, the questions that are asked in the community are very mixed. Some are surprisingly new and really creative. Issues are discussed that I never had thought of doing or even asking about.

Vargo and Lusch (2004) point to the importance of learning from customers, and Bagozzi and Dholakia (2006) encourage firms to treat customers as partners, because 
customers represent external information sources who can enrich existing knowledge stocks through the addition of a new perspective.

Furthermore, customers as bidirectional creators add further knowledge because they exchange experiences with working with the products and services, and hence provide contextual information. Especially in technical environments, customers use combinations of products and services that companies might not have been tested before, as one customer [Martin] states:

The community and the presented solutions are better, as customers often really have the experience on what definitely works. Sometimes the people in the support center do not necessarily know what is going on in our [customers'] environments. The customer community goes beyond just problem solving because it offers experience and backup; it is one thing to know how a product works, but it is another thing to know how a product works in the real world and in relation to other products.

Hence, bidirectional creators provide companies with contextual knowledge. Both Brown and Duguid (1991) and McLure Wasko and Faraj (2000) point to the importance of context in constructing learning experiences, because knowledge disconnected from practice distorts and complicates the details of that practice, whereas the context offers information about situations, intentions, and feelings pertaining to an issue or action. Understanding the customer context enables companies to think more effectively, prioritize information, and frame issues and decisions. Despite providing knowledge about different applications and environments, customers also provide multiple answers to the same problems, which increases the learning possibilities for both the company and other customers. Another customer [Philip] clarifies:

Every person has another experience of a particular problem and how they solved it. When I have a problem and 10 people reply, I receive at least 5 different answers. I once tried different approaches on an old machine that we had and I was really surprised that all of them worked.

Because the community provides a platform for transparent knowledge coproduction, customers generally are grateful for the learning opportunities. When the customers learn in advance about potential problems, they are better prepared, which reduces the assistance costs for the company; the focal company estimates that $40 \%$ of service calls from customers with a service contract could be avoided if they visited the online technical support community. According to one customer [Wayne],

I can expand my existing knowledge without devoting a lot of time and creating costs. The learning effect is enormous; sometimes I read things and I wonder why I never tried that myself. So, in the future when the problem will come, I will know a solution immediately.

In addition, knowledge is self-generative in the sense that one piece of knowledge creates conditions for subsequent information. By giving customers an opportunity to learn more, companies enhance their skills in understanding, using, operating, modifying, and/or repairing a product. However, bidirectional creators also post negative feedback openly, for any customer to read, as the following example posting from the virtual customer community shows:

I've been working with [the company] going on 11 years now and have called for hardware and software support a few times over the past year and have noticed the service slide into a deep dark abyss, other than this forum does anyone know where or what link I can use to complain to [the company]!?

When faced with such comments, the company can react to such negative feedback and use it as stimulus for innovation.

However, whereas the passive user and active informer roles focus purely on functionality, the bidirectional creator also wants social interactions. The community provides an ideal place where customers (and the company) not only exchange task-related information but also form interpersonal relationships, as several customers indicate:

We feel a sense of belonging. In the community, you meet other people who have the same interests. You have an opportunity to get together and discuss things. [Philip]

I like the community because of the social interaction with people from different companies and different backgrounds. We also have social interactions, for example on career opportunities or jokes related to our jobs. [Aaron]

A study by Nambisan (2002) discusses the qualifications customers need to support one another, including experience and knowledge through their usage of products and services. Furthermore, the community facilitates knowledge coproduction because peer customers share similar service experiences, which provides them with a better understanding of one another and contributes to the potential for product support success. In summary, customers can serve as bidirectional creators, the highest level of knowledge coproduction, by contributing to the solution of problems and creating new knowledge themselves.

Impact of customer coproduced knowledge on innovation

When customers coproduce knowledge in electronic services, companies may use the knowledge about service 
content and delivery for their innovation efforts. That is, knowledge may be categorized into two general topics, according to a team member of the Web service management and outbound marketing [Teresa]:

We make a differentiation between feedback on the content itself and feedback on the structure of our websites. In the first level, we analyze the feedback on the quality of the content whereas in the second level we analyze the feedback searching for information on, for example, a missing link.

In addition, all created knowledge arrives in a relatively cost-effective manner. Instead of organizing expensive meetings with a limited number of customers, such as focus groups, the company receives easily tracked knowledge during their daily operations. The program manager for electronic service delivery [Timothy] states:

There is also a financial aspect, as a one-on-one meeting where we ask customers on their opinions will cost us a lot of money. If we invite the customer to provide feedback on a normal daily business basis, we receive customer feedback that is more operational and presents a cheaper solution to receive customers' opinions.

Thus, the knowledge coproduction becomes part of the daily operations. Continuously tracking customers' information provides an early alert mechanism for new and changing customer needs (Urban and Hauser 2004) and is much more effective and accurate than it would be in some artificial situation (Nambisan 2002).

Companies use customer coproduced knowledge differently in their innovation activities, which involve not simply a discrete event but rather as a process over time (Yadav et al. 2007) that comprises detection, development, and deployment of a new product or service. First, firms must detect an unfulfilled customer need; that is, detection refers to the identification of a new product or service idea. Second, they must develop the new product or service, so development refers to the conversion of an idea into a product or service launched into the market. Third, companies must deploy the new product or service by exploiting additional features and improving existing features of the launched product or service (see Slotegraaf et al. 2003).

\section{Detection}

Customer coproduced knowledge helps companies identify problem areas, as an inbound marketing manager [Joe] explains:

Based on the customer input, we have developed some new products and services, e.g., the usage of the web interface has been improved. Through the customer feedback, we realized that a certain document type created problems, so we developed a solution for that. We can check these kinds of information and initiate an innovation project to eliminate the problems. We also detect new product directions and get insights into where they should take their products in the future.

But customers do not only help companies identify problem areas; they also provide concrete suggestions and ideas. The operational community manager [David] indicates:

I actually go out there regularly and solicit feedback to look for enhancements and idea suggestions. Accordingly, a roadmap is created and the developers get their action items.

In addition, monitoring customer's natural Internet behavior could identify opportunities for innovation (Urban and Hauser 2004). More customers participate in this setting than in focus groups and market surveys, which enhances the representativeness of the information. Furthermore, companies can use passive users to detect unfulfilled needs. As a manager for knowledge integration [Jeremy] explains:

There have been some issues that we could identify through the tracking of the customer behavior, like seeing which documents are perceived as useful and which ones are not used at all. This shows us the priorities of our customers. But beyond, we do not get a lot of information on how customers see our products and services.

Because the knowledge created by a passive user mainly reflects customer behavior, it has high representativeness; a program manager for a specific part of electronic services [Pamela] points out that

The information from tracking customers' behavior is very representative. Therefore, we can be sure that the knowledge we build from that information is widely applicable to many customers.

In turn, companies can detect latent needs. Listening to customers may lead only to imitative, unimaginative products (Nambisan 2002), so though observing customers' behavior gives companies a direction for their ideas, it remains up to the company's creative team to innovate the product. In contrast, an active informer does not offer representativeness, which reduces the company's confidence in that coproduced knowledge. As a manager for service delivery engineering productivity tools [George] states,

We really use the feedback that customers send to us, but the feedback itself is not enough, because it is not representative at all. Only a small number of customers send us feedback at the moment. We cannot be sure that our conclusions from the feedback are really correct. 
Although the knowledge coproduced by bidirectional creators also often originates from a small group of customers, their interactions with the firm are perceived more intensely. When the customer provides not only information but specific knowledge, employees consider those customers highly educated and knowledgeable. In contrast, information from passive users is representative but does not indicate customers' perceptions. Thus, the experience-rich, solutioncentered conversations of bidirectional creators are a critical resource for detecting new ideas. The bidirectional creator critically affects innovation detection, because employees can follow entire customer conversations. One country e-service manager [Patrick] explains:

Our engineers receive a higher variety of answers from many different customers. The customers are using the products and typically the best information is from people who have literally done that and maybe not our official textbook support.

Therefore, employees learn from customer coproduced knowledge by increasing their understanding of the customers' environment. Whereas customers usually need to be prompted to participate in innovation activities and seldom offer unsolicited new ideas, bidirectional creators who participate in virtual communities partly fulfill their own needs to earn recognition, enhance their self-esteem, and engage in helping behavior (e.g., McLure Wasko and Faraj 2000). This fulfillment is fostered mainly by the social relationships that develop among customers and employees in the virtual community and that increase knowledge-sharing behavior (e.g., McLure Wasko and Faraj 2000). Capturing customer knowledge thus fuels the knowledge creation process for innovation (Nambisan 2002) because customers should play essential innovation roles (Lilien et al. 2002).

\section{Development}

Development refers to the conversion of a new idea into a new product or service launched on the market. Collaboration with customers requires them to play active roles, so passive users cannot contribute to development. Active informers also cannot contribute to development, because their communication is unidirectional. However, bidirectional creators help the development team in various ways, such as validating product architectural choices. An inbound marketing manager [Joe] explains:

The knowledge created by customers is a validation of what we already know. It is easier for us to improve our knowledge and we can assure that we have made the right decisions.
Especially in highly dynamic market situations, changes might be so rapid that information collected at the beginning of an innovation project becomes obsolete during the project. Repeated interactions with customers confirm new products and services during development, because monitoring changing market conditions and including customer needs, enhances an organization's market knowledge and thus its innovation efforts. Furthermore, the company can ask customers about new features and requirements, as the community development manager [Robert] points out:

In the past we have used the community to test new product areas. We have seen development groups that have used customer feedback. Our development teams were thinking about some new ideas for a product, and they asked things like "how would you like that in the future" or "what do you think about this feature?". So, we can save thousands of dollars by just asking these people and not organizing a focus group for every little feature.

Several studies highlight the potential for using customers from virtual communities for product testing (Bagozzi and Dholakia 2006; Jeppesen and Frederiksen 2006), which reduces the costs of internal product testing units and provides real-life feedback early in the development process, potentially limiting costly, time-consuming rework and redesign requirements in later stages. Companies also might involve a variety of customers to gain a better understanding of how the product and/or service functions in different customer environments (Nambisan 2002). In an open environment such as the customer community, customers interact during product testing and may clarify their ideas, suggestions, and feedback to the company. Furthermore, their involvement facilitates the product launch because many customer participants become advocates for the new product or service, though early adopters also might be more enthusiastic about the prototype and therefore accept lower quality levels. As a consequence, companies might develop a blind spot with regard to new product deficiencies. Furthermore, active customer involvement is difficult to coordinate and may be more time consuming, especially if customers are relatively slow to provide feedback. When customer feedback comes too late in the development stage, it might lead to design defects, mismanaged expectations, and budget or schedule overruns. Therefore, development teams must carefully manage active customer involvement.

\section{Deployment}

Deployment refers to the exploitation of additional features and improvements to existing features of the launched 
product or service, and in this stage, all three customer roles can be of assistance. Observing passive user behavior helps companies determine where customers need the most help with respect to newly developed products. Active informers tell companies about specific problems, and bidirectional creators provide specific solutions. After the launch of a new product or service, customers are often the first to find and report errors (Jeppesen and Frederiksen 2006). As the community development manager [Robert] notes:

When we learn from all the customer knowledge, we can improve our existing service capabilities, as well as gather insights for our development projects.

Knowledge coproduction by customers and the resulting increase in organizational knowledge also influences perceived service quality through various means. For example, the organization uncovers customer requirements and service expectations, according to the inbound marketing manager [Joe]:

Once we have received all customer created knowledge, we know about customers' experiences with our products and services, what they did and whether they found the necessary information. For example, we gain knowledge about broken hyperlinks, etc. We also get to know how and for what purposes the customers use our sites and what technical issues are important. We can use this knowledge to deliver better services, as we get a better feeling for what they want.

Understanding customer requirements helps organizations deliver better services (e.g., Sheth et al. 2000). Furthermore, if organizations exploit the dynamics of electronic services, they can provide the most recent information to their customers. The program manager of the system usage team [Charles] states:

Customers can get information on the latest problems, the latest updates, so they receive very recent information. Usually they get higher quality documents, as we received feedback on these documents and incorporated that into the documents.

That is, the more knowledge customers coproduce, the more the organization learns about their requirements and the better it can serve them. If companies fail to encourage knowledge coproduction, they miss significant opportunities, as a business development manager [Matthew] argues:

By discarding the customer feedback and comments, we miss the opportunity of improving the quality of our support content, enhancing our service delivery tools, and increasing overall customer satisfaction.

Consistent with existing literature, more knowledgeable employees better deliver services that match customer needs (Roth and Jackson 1995), help reduce organizational uncertainty, decrease process variability, and advance a firm's ability to adjust to new conditions. Furthermore, when customers coproduce knowledge, they feel like part of the service and closer to the organization. In turn, they often gain a better understanding of the organization's situation and might be more tolerant of mistakes. The continuous deployment and customer contributions to products and services therefore may result in longer product lives and improved sales (Jeppesen and Frederiksen 2006).

\section{Conclusions and implications}

We have contributed to theory development by exploring how customers coproduce knowledge for different innovation tasks. Two research questions guided this study: (1) Can we identify specific customer roles for knowledge coproduction in electronic services? and (2) How can customer knowledge coproduced in knowledge services be of benefit to various innovation tasks? In this study, we have shown that customers can take on three different roles for knowledge coproduction in electronic services-passive user, active informer, and bidirectional creator - each with distinctive declarative and procedural characteristics. We have also demonstrated that each role has a distinct impact on the three innovation tasks of detection, development, and deployment.

This study makes three important contributions to the literature on company-customer collaboration in services marketing. First, it shows explicitly how S-D logic can help companies to manage knowledge from company-customer collaborations. It thereby specifically looks at a combination of Vargo and Lusch's (2004) foundational premises 4 (knowledge is the fundamental source of competitive advantage) and 6 (the customer is always a cocreator) within an innovation context. It goes beyond existing research on company-customer collaboration research by not only looking at the cost advantages for companies or specific features of the interaction, but also incorporating positive aspects for future performance improvements through knowledge coproduction. Second, we show how companies can institute customers as exchange partners for joint knowledge creation. Therefore, we have chosen the service provider view, as customers might not always be aware of their knowledge coproduction for companies, as for example shown in the role of passive user. Third, we discuss the social dimension of interactions between company and customer and also between customers in the online community. So far, most research on customer collaboration has considered joint production or customer self-production, but has not looked at how customers produce a service for another customer, as part of the bidirectional creator. 
We find that these interactions add a human, social dimension that is highly valued by participating customers. Future research might want to further investigate this phenomenon.

Furthermore, our study also contributes to the literature on company-customer collaboration in innovation. First, we show how customer coproduced knowledge can contribute in every stage of the innovation process. Especially by increasing the number of connection points between company and customers, customers cannot only provide a one shot evaluation of a product or service in development, but rather be involved in various innovation tasks. Second, we illustrate how companies can do so in a daily business setting. Hence, they can eliminate some of the cost for market research while information might be more upto-date than from a market research that has been done, for example, 3 months ago. We do not argue that all market research should be eliminated; rather we want to demonstrate that companies can chose from a larger set of alternatives to involve customers. Third, we identify opportunities for inferring latent needs from dialogues between customers. Involving customers in innovation has sometimes been criticized to only leading to incremental innovation. A lot of customer coproduced knowledge relates to existing products and services and might therefore rather steer incremental innovation. However, bidirectional creators also contribute solutions and innovative combinations of knowledge. Hence, assuming some creative potential, companies can infer latent needs from these dialogues.

\section{Suggestions for further research}

Our initial inquiry fails to consider a few issues. For example, we use multiple sources of information and an iterative analysis procedure to increase the validity of our constructs and the presumed correctness of our inferences (Yin 1994), and the external validity of our case studies points to analytical generalizability. However, because this case study aims only to develop theory rather than test that theory, further research may wish to validate some of our findings. For example, it might be interesting to investigate how specific company-customer collaborations change over time, whether customer coproduced knowledge leads to more ideas, improves conversion ability of ideas, or whether customers partly take over ownership of a new product or service if they consciously coproduced knowledge.

Moreover, this study was conducted in the computer industry which has a tradition for collaboration in innovation. In other industries, companies might first have to educate customers in how they can coproduce knowledge. However, the interconnections between customers and companies are also increasing in other industries.
Furthermore, we take the service provider view in looking at customer roles and their resultant impact on innovation activities. Future research could take on the customer perspective and for example investigate what happens when customers (want to) switch between roles, under what circumstances they do not want to coproduce knowledge, maybe out of confidentiality reasons or fear of self-embarrassment. Hence, it also remains important for practice and theory to examine why customers might take the time and effort to share their information and knowledge. The customers we interviewed for our case study spent an averaged $13 \mathrm{~h}$ per week in the community to help other customers and provide advice. It would be interesting to investigate their motivation and determine why customers coproduce knowledge.

Acknowledgement The authors thank Matthew Meuter for his comments on a previous version of the manuscript.

\section{References}

Alam, I. (2002). An exploratory investigation of user involvement in new service development. Journal of the Academy of Marketing Science, 30(3), 250-261.

Aubert-Gamet, V. (1997). Twisting servicescapes: Diversion of the physical environment in a re-appropriation process. International Journal of Service Industry Management, 8(1), 26-41.

Bagozzi, R. P., \& Dholakia, U. M. (2006). Antecedents and purchase consequences of customer participation in small group brand communities. International Journal of Research in Marketing, 23 (1), 45-61.

Bendapudi, N., \& Leone, R. P. (2003). Psychological implications of customer participation in co-production. Journal of Marketing, 67, 14-28. (January)

Bettencourt, L. A. (1997). Customer voluntary performance: Customers as partners in service delivery. Journal of Retailing, 73(3), 383-406.

Bitner, M. J., Faranda, W. T., Hubbert, A. R., \& Zeithaml, V. A. (1997). Customer contributions and roles in service delivery. International Journal of Service Industry Management, 8(3), 193-205.

Bowers, M. R., Martin, C. L., \& Luker, A. (1990). Trading places: Employees as customers, customers as employees. Journal of Services Marketing, 4(2), 55-69.

Brown, J. S., \& Duguid, P. (1991). Organizational learning and communities of practice: Toward a unified view of working, learning and innovation. Organization Science, 2(1), 40-57.

Dabholkar, P. A., \& Bagozzi, R. P. (2002). An attitudinal model of technology-based self-service: Moderating effects of consumer traits and situational factors. Journal of the Academy of Marketing Science, 30(3), 184-201.

Dolan, R. J., \& Matthews, J. M. (1993). Maximizing the utility of customer product testing: beta test design and management. Journal of Product Innovation Management, 10(4), 318-330.

Glaser, B. G., \& Strauss, A. L. (1967). The discovery of grounded theory: Strategies for qualitative research. Hawthorne, NY: Aldine de Gruyter.

Gruen, T. W., Summers, J. O., \& Acito, F. (2000). Relationship marketing activities, commitment, and membership behaviors in professional associations. Journal of Marketing, 64(3), 34-49. 
Holsti, O. R. (1969). Content analysis for the social sciences and humanities. Reading, MA: Addison-Wesley.

Jeppesen, L. B., \& Frederiksen, L. (2006). Why do users contribute to firm-hosted user communities? The case of computer-controlled music instruments. Organization Science, 17(1), 45-63.

Kelley, S. W., Donnelly Jr., J. H., \& Skinner, S. J. (1990). Customer participation in service production and delivery. Journal of Retailing, 66(3), 315-335.

Lengnick-Hall, C. A. (1996). Customer contributions to quality: A different view of the customer-oriented firm. Academy of Management Review, 21(3), 791-824.

Lilien, G. L., Morrison, P. D., Searls, K., Sonnack M., \& von Hippel, E. (2002). Performance assessment of the lead user idea-generation process for new product development. Management Science, 48 (8), 1042-1059.

Lovelock, C. H., \& Young, R. F. (1979). Look to consumers to increase productivity. Harvard Business Review, 57/3, 168-178. (May/June)

Lusch, R. F., \& Vargo, S. L. (2006). Service-dominant logic: Reactions, reflections, and refinements. Marketing Theory, 6(3), 281-288.

Lusch, R. F., Vargo, S. L., \& O'Brien, M. (2007). Competing through service: Insights from service-dominant logic. Journal of Retailing, 83(1).

McLure Wasko, M., \& Faraj, S. (2000). It is what one does: Why people participate and help others in electronic communities of practice. Journal of Strategic Information Systems, 9(2-3), 155-173.

Meuter, M. L., Ostrom, A. L, Roundtree, R. I., \& Bitner, M. J. (2000). Self-service technologies: Understanding customer satisfaction with technology-based service encounters. Journal of Marketing, 64(3), 50-64.

Meuter, M. L., Bitner, M. J., Ostrom, A. L., \& Brown, S. W. (2005). Choosing among alternative service delivery modes: An investigation of customer trial of self-service technologies. Journal of Marketing, 69(2), 61-83.

Miles, M. B., \& Huberman, A. M. (1994). Qualitative data analyses. Thousand Oaks, CA: Sage Publications.

Nambisan, S. (2002). Designing virtual customer environments for new product development: Towards a theory. Academy of Management Review, 27(3), 392-413.
Prahalad, C. K., \& Ramaswamy, V. (2004). The future of competition: Co-creating unique value with customers. Boston: Harvard Business School Press.

Prahalad, C. K., \& Ramaswamy, V. (2003). The new frontier of experience innovation. Sloan Management Review, 12-18. (Summer)

Roth, A. V., \& Jackson III, W. E. (1995). Strategic determinants of service quality and performance: Evidence from the banking industry. Management Science, 41(11), 1720-1733.

Sawhney, M., \& Prandelli, E. (2000). Communities of creation: Managing distributed innovation in turbulent markets. California Management Review, 42(4), 24-54.

Sheth, J. N., Sisodia, R. S., \& Sharma, A. (2000). The antecedents and consequences of customer-centric marketing. Journal of the Academy of Marketing Science, 28(1), 55-66.

Sismeiro, C., \& Bucklin, R. E. (2004). Modeling purchase behavior at an e-commerce web site: A task-completion approach. Journal of Marketing Research (JMR), 41(3), 306-323.

Slotegraaf, R. J., Moorman, C., \& Inman, J. (2003). The role of firm resources in returns to market deployment. Journal of Marketing Research, 40(3):295-309.

Spiggle, S. (1994). Analysis and interpretation of qualitative data in consumer research. Journal of Consumer Research, 21, 491-503. (December)

Urban, G. L., \& Hauser, J. R. (2004). Listening in to find and explore new combinations of customer needs. Journal of Marketing, 68 , 72-87. (April)

Vargo, S. L., \& Lusch, R. F. (2004). Evolving to a new dominant logic for marketing. Journal of Marketing, 68, 1-17. (January)

von Hippel, E. (1986). Lead users: A source of novel product concepts. Management Science, 32(7), 791-805.

von Hippel, E., \& Katz, R. (2002). Shifting innovation to users via toolkits. Management Science, 48(7), 821-833.

Yadav, M. S., Prabhu, J. C., \& Chandy, R. (2007). Managing the future: CEO attention and innovation outcomes. Journal of Marketing, 71(4).

Yin, R. K. (1994). Case study research: Design and methods. Thousand Oaks: Sage Publications. 